\title{
Evolution of EIS properties of composite polymer protective coatings in corrosive media
}

\section{V.A. Golovin * and S.A. Dobriyan}

\author{
A.N. Frumkin Institute of Physical Chemistry and Electrochemistry, Russian Academy \\ of Sciences, Leninskii pr. 31, 119071 Moscow, Russian Federation \\ E-mail: golovin@rocor.ru
}

\begin{abstract}
Electrochemical impedance spectroscopy (EIS) was used for a comparative study of the evolution of the electrochemical characteristics of protective primers, inert insulating coatings, and multilayered polymer composite coatings in chloride media. It was shown that the layers of coating with inert fillers on an inert substrate could be described as the simplest equivalent circuit (EC) with a single characteristic relaxation process in the entire range of exposure times. The same EC describes coatings on a potentially corroding substrate at the initial exposure stage. Later, as underfilm corrosion develops, the EC evolves into a system with two relaxation processes. In thin-layer systems with an active filler $(\mathrm{Zn})$, the two relaxation processes are manifested starting from the initial exposure period. In thick multilayered composite coatings that contain spatially separated layers with reactive and inert fillers on a corroding steel substrate, three characteristic relaxation times are observed. These findings agree with the model of multiphase laminated volume-filled polymer composite materials and provide a justification to the usage of Voigt's additive ECs. Using this approximation, we performed a description of all EIS data for all the systems we considered at various temperatures, including inert layers based on steel and platinum, thin and multilayered $\mathrm{Zn}$-rich primer layers, and multilayered coatings made of these materials. The results obtained allowed us to suggest a technique of nondestructive EIS monitoring of the physicochemical and corrosion processes in composite polymer protective coatings. The technique is based on performing comparative electrochemical impedance spectroscopy on various metal (corroding and inert) substrates at various temperatures and identification of the processes using characteristic frequencies, effective activation energies, and corrosion rate during exposure.
\end{abstract}

Received: September 29, 2021. Published: October 28, 2021

doi: $\underline{10.17675 / 2305-6894-2021-10-4-8}$

Keywords: corrosion protection, polymer coatings, underfilm corrosion, electrochemical impedance spectroscopy, equivalent circuit.

\section{Introduction}

Multilayered composite coatings that contain a layer of a Zn-rich primer and upper layers made of an insulating polymer paint are efficient means for protection against corrosion [1]. The use of such coatings, which significantly simplifies the technology for the protection of carbon steels, is an alternative to conventional zinc plating. 
However, the mechanism of the protective effect of multilayered composite coatings with active metal anticorrosion additives has not been studied yet in sufficient detail. One of the reasons is that $\mathrm{Zn}$ particles in composite coatings with upper insulating layers are located in an internal corrosive medium that differs from the external $\mathrm{NaCl}$ solution. This changes both the thermodynamics and kinetics of electrochemical processes. Due to this, the scientific basis for the efficient protection by multilayered composite materials containing metal additives has been formulated in only fragmentary form to date [2-6].

This situation is essentially due to the lack of nondestructive techniques that would allow a comprehensive study of electrochemical processes on both the protected substrate, the primer layer, and the upper insulating paint layer on long-term exposures in corrosive media.

The purpose of this study was to clarify the mechanism of the protective effect of composite coatings and estimate the electrochemical and insulating properties of both individual layers and the entire multilayered composite coatings by means of electrochemical impedance spectroscopy (EIS).

\section{Objects and Methods}

The objects under study included individual coatings made of commercial Zn-rich protective primer METACOR-01 (M-01) TU (Technical requirements) 2312-003-11490792-99, epoxy coating ROCOR-5095 (R-5095) TU 2312-042-11490792-09, and composite coatings on their basis.

We have studied the behavior of these coatings under long-term exposure in $3 \% \mathrm{NaCl}$ solution on an inert (platinum, $\mathrm{Pt}$ ) and corroding ( $\mathrm{St} 3$ steel) substrate at temperatures ranging from $20^{\circ} \mathrm{C}$ to $80^{\circ} \mathrm{C}$.

Electrochemical impedance spectroscopy (EIS) [7-9] combined with the potentiometry method were the main tools of the study. The area of the working electrode (coated sample) was $6.2 \mathrm{~cm}^{2}$.

Impedance was studied using a FRA-1 analyzer developed by the Institute of Physical Chemistry and Electrochemistry of the Russian Academy of Sciences, by the ISO methodology recommended for polymer coatings [10] in a frequency range of $(100 \mathrm{kHz}-$ $0.1 \mathrm{~Hz}$ ). The area of the auxiliary platinum electrode was $16.9 \mathrm{~cm}^{2}$; this value is sufficient for our purposes, as confirmed by the fact that a reduction in this area did not affect the measured results. The equivalent electric circuit parameters were calculated in the DCS program based on the spectra obtained.

The potential of the substrates with coatings was determined directly in the cell for impedance measurement with respect to the silver-chloride electrode using the following circuit: sample under study / working solution / saturated $\mathrm{KCl} / \mathrm{AgCl} / \mathrm{Ag}$ with an auxiliary platinum electrode. All potentials are reported against the standard hydrogen electrode. 


\section{Results and Discussion}

\subsection{Individual coatings}

Multilayered composite coatings are known to contain several layers differing in composition, including metal-rich primers and upper layers made of inert formulations. The system approach prompts that in studying the properties of composite systems, it is reasonable to consider first the EIS results of estimating the electrochemical properties of individual layers of composite coatings; namely, the insulating inert paint layer and the Znprotective polymer primer. It is also reasonable [11] to estimate the behavior of these coatings on both inert $(\mathrm{Pt})$ and corroding $(\mathrm{St} 3)$ substrates.

\subsubsection{Inert coating $R-5095$ on platinum and steel}

The Figures below display the hodographs and frequency plots of the dielectric loss tangent (Bode plots) for the electrochemical impedance of epoxy enamel R-5095 with an inert filler $\left(\mathrm{TiO}_{2}\right)$ on a platinum (Figures 1 and 2) and steel (Figures 3 and 4) substrates in the course of exposure in $3 \% \mathrm{NaCl}$ solution. Table 1 contains the results of calculations using the equivalent circuits.

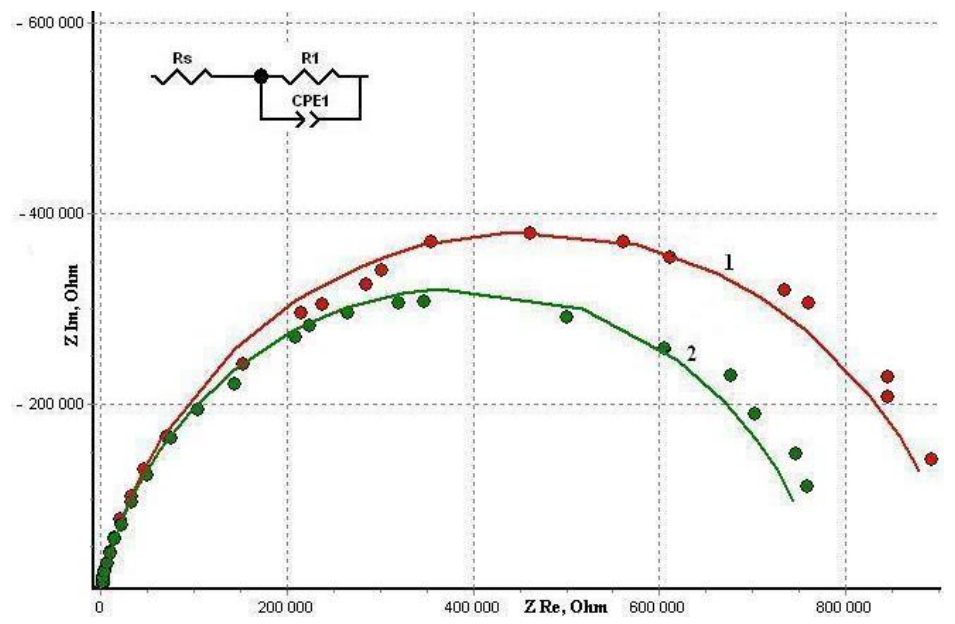

Figure 1. Impedance hodograph of coating R-5095 with an inert filler $\left(\mathrm{TiO}_{2}\right)$ on a platinum substrate after exposure in $3 \% \mathrm{NaCl}$ solution for 30 days (1) and 160 days (2). Dots experimental data; lines - EC-based calculation.

The shape of the impedance hodograph for inert insulating enamel R-5095 on an inert Pt substrate, which was the same for all times of exposure in $3 \% \mathrm{NaCl}$ solution in a range of frequencies from $25 \mathrm{kHz}$ to $6 \mathrm{~Hz}$, can be represented as a semicircle with a displaced center.

As the exposure time increases, the quantitative characteristics of the impedance hodograph (Figure 1) and frequency plot of the dielectric loss tangent on the Bode plot (Figure 2) do not change much. This behavior corresponds to the existence, in the frequency range down to $6 \mathrm{~Hz}$, of a single relaxation process with a characteristic frequency of about $5 \mathrm{kHz}$. 


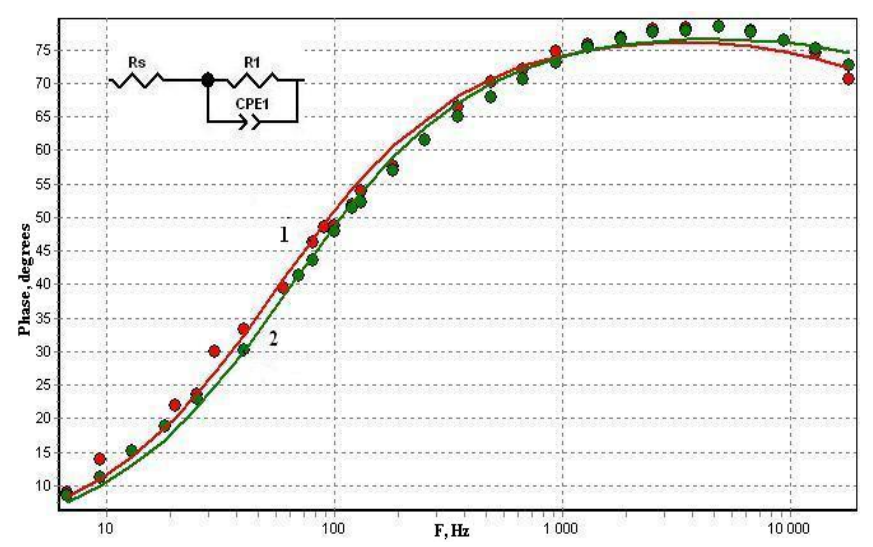

Figure 2. Bode plot for coating R-5095 with an inert filler $\left(\mathrm{TiO}_{2}\right)$ on a platinum substrate after exposure in $3 \% \mathrm{NaCl}$ solution for 30 days (1) and 160 days (2). Dots - experimental data; lines - EC-based calculation.

The description of the EIS of the same coating on steel (St3 GOST mark) is more complex. In particular, primary data (Figure 3) for the frequency range under consideration show that the EIS characteristics at the initial stage of exposure are qualitatively similar to the dependences for the inert Pt substrate, although the absolute values of the impedance on St3 are somewhat smaller. However, the frequency dependence of the dielectric loss tangent on the Bode plot for St3 and Pt have virtually the same magnitude. This can be considered as an indication that no active underfilm corrosion process occurs under coating R-5095 on St 3 at the initial stage of exposure (up to 30 days).

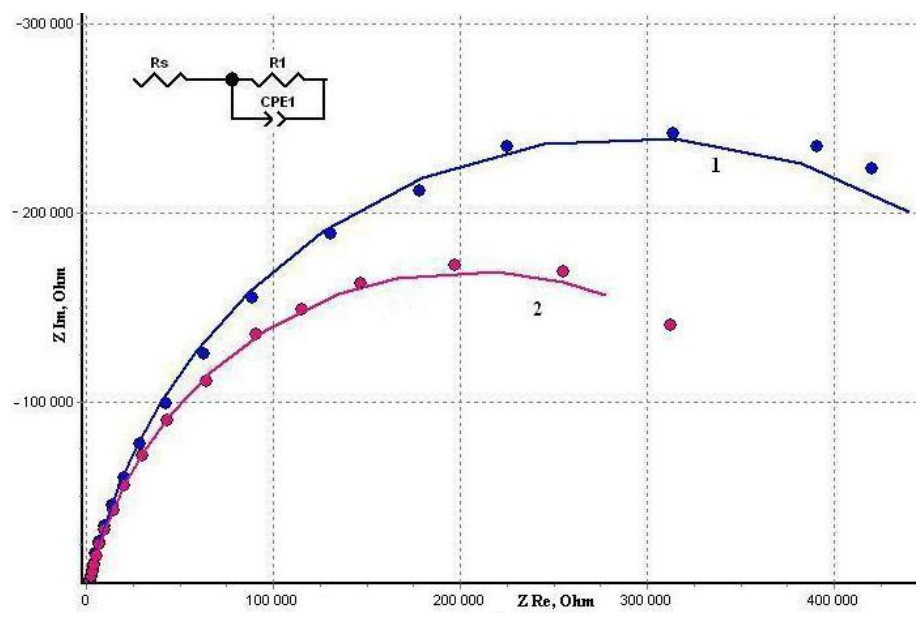

Figure 3. Impedance hodograph of coating R-5095 with an inert filler $\left(\mathrm{TiO}_{2}\right)$ on a platinum substrate after exposure in $3 \% \mathrm{NaCl}$ solution for 14 days (1) and 30 days (2). Dots experimental data; lines - EC-based calculation.

At longer exposure times, the shape of the hodograph on St3 becomes more complex (Figure 5). EIS analysis allows the identification (apart from Warburg impedance) of two relaxation processes (Figure 6) with high frequency (HF) and medium frequency (MF) in the frequency range under consideration. 


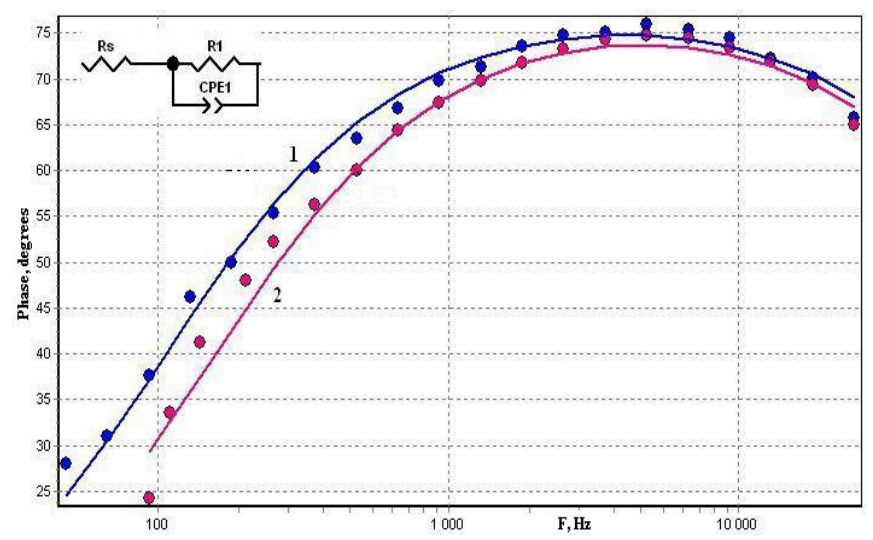

Figure 4. Bode plot for coating R-5095 with an inert filler $\left(\mathrm{TiO}_{2}\right)$ on a platinum substrate after exposure in $3 \% \mathrm{NaCl}$ solution for 14 days (1) and 30 days (2). (Dots - experimental data; lines - EC-based calculation).

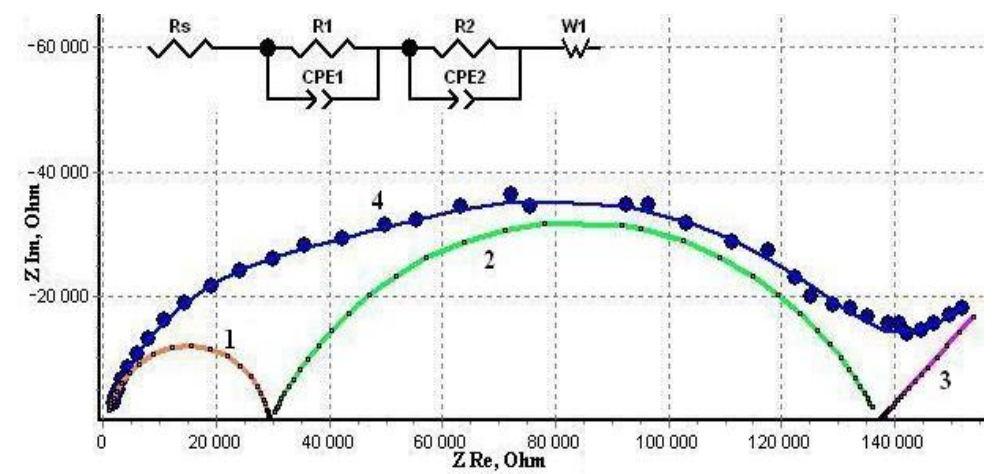

Figure 5. Impedance hodograph of coating R-5095 with the inert filler $\left(\mathrm{TiO}_{2}\right)$ on a steel (St3) substrate after exposure in 3\% NaCl solution for 160 days. Big dots - experiment; lines - ECbased calculation: 1 -HF process, 2 - LF process, 3 - Warburg impedance, 4 - integral plot.

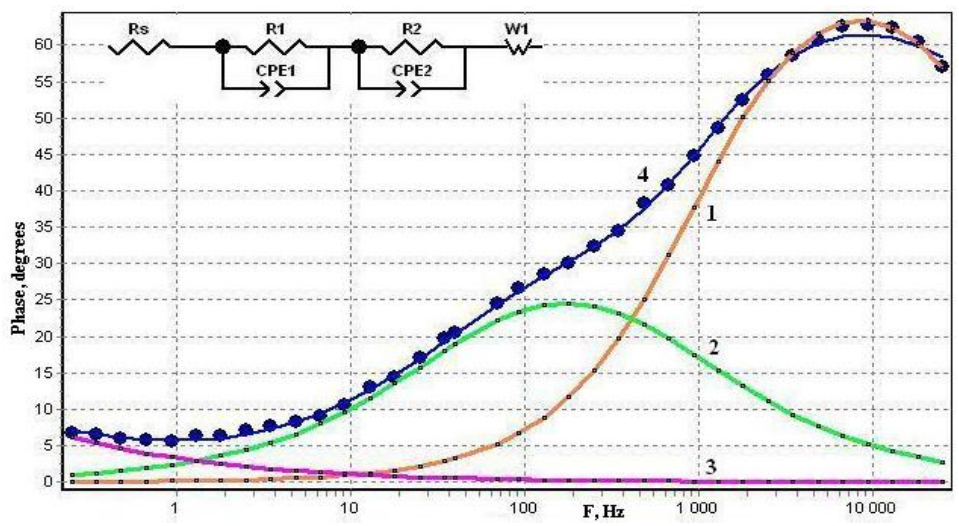

Figure 6. Bode plot for the impedance of coating R-5095 with the inert filler $\left(\mathrm{TiO}_{2}\right)$ on a steel (St3) substrate after exposure in 3\% $\mathrm{NaCl}$ solution for 160 days. Big dots experiment; lines - EC-based calculation: 1 - HF process, 2 - LF process, 3 - Warburg impedance, 4 - integral plot.

The parameters of relaxation processes and the values of EC elements for R-5095 coating on Pt and St3 are presented below. 
Table 1. Evolution of electrochemical parameters of coating R-5095 on Pt and St3 upon exposure in 3\% $\mathrm{NaCl}$ solution at $25^{\circ} \mathrm{C}$ for the ECs (Figures 3 and 5) in a frequency range of $25000-2 \mathrm{~Hz}$ based on processing primary EIS data.

\begin{tabular}{cccccc}
\hline & \multicolumn{5}{c}{ Exposure, days } \\
\cline { 2 - 6 } $\begin{array}{c}\text { Characteristics of the } \\
\text { coating/substrate system }\end{array}$ & $\mathbf{7}$ & $\mathbf{3 0}$ & $\mathbf{6 0}$ & $\mathbf{1 3 0}$ & $\mathbf{1 6 0}$ \\
\cline { 2 - 6 } & $8.21 \cdot 10^{5}$ & $7.71 \cdot 10^{5}$ & $9.35 \cdot 10^{5}$ & $8.54 \cdot 10^{5}$ & $6.87 \cdot 10^{5}$ \\
\hline$R 1$, Ohm & $4.58 \cdot 10^{-9}$ & $5.23 \cdot 10^{-9}$ & $4.88 \cdot 10^{-9}$ & $6.14 \cdot 10^{-9}$ & $5.56 \cdot 10^{-9}$ \\
CPE-T1, F & 3474 & 4827 & 3474 & 4827 & 4827 \\
$\begin{array}{c}\text { Characteristic frequency of the } \\
\text { HF process, Hz }\end{array}$ & 313 & 364 & 418 & 589 & 563 \\
Substrate potential (SHE), $\mathrm{mV}$ & & &
\end{tabular}

\begin{tabular}{|c|c|c|c|c|c|}
\hline \multirow{3}{*}{$\begin{array}{l}\text { Characteristics of the } \\
\text { coating/substrate system }\end{array}$} & \multicolumn{5}{|c|}{ Exposure, days } \\
\hline & 7 & 30 & 60 & 100 & 160 \\
\hline & \multicolumn{5}{|c|}{ St3 substrate } \\
\hline$R 1, \mathrm{Ohm}$ & $7.36 \cdot 10^{5}$ & $4.12 \cdot 10^{5}$ & $1.17 \cdot 10^{5}$ & $8.32 \cdot 10^{4}$ & $2.87 \cdot 10^{4}$ \\
\hline CPE-T1, F & $4.99 \cdot 10^{-9}$ & $6.11 \cdot 10^{-9}$ & $6.83 \cdot 10^{-9}$ & $9.29 \cdot 10^{-9}$ & $1.25 \cdot 10^{-8}$ \\
\hline $\begin{array}{c}\text { Characteristic frequency of the } \\
\text { HF process, Hz }\end{array}$ & 4827 & 4827 & 9319 & 9319 & 9319 \\
\hline$R 2, \mathrm{Ohm}$ & - & - & $2.73 \cdot 10^{5}$ & $1.46 \cdot 10^{5}$ & $1.16 \cdot 10^{5}$ \\
\hline CPE-T2, F & - & - & $1.72 \cdot 10^{-7}$ & $1.42 \cdot 10^{-7}$ & $1.87 \cdot 10^{-7}$ \\
\hline $\begin{array}{c}\text { Characteristic frequency of the } \\
\text { MF process, } \mathrm{Hz}\end{array}$ & - & - & 18 & 67 & 180 \\
\hline Substrate potential (SHE), mV & 91 & -35 & -93 & - & -100 \\
\hline
\end{tabular}

The primary EIS data and processing of these data show that:

- The hodographs and frequency dependences for inert coating R-5095 on Pt virtually do not change during exposition. The calculated values of the active and capacitive EC components and the characteristic frequency of the relaxation process do not change, either. It should be noted that the potential of the Pt substrate expectedly increased by $250 \mathrm{mV}$.

- However, in the case of the same coating R-5095 on the steel (St3) substrate, both primary and calculated characteristics change. It should be noted first of all that an 
additional MF relaxation process emerges in the system concurrently with changes in the quantitative characteristics of the HF process.

- The main changes in the HF region are as follows: a) active resistance R1 decreases; b) the loss tangent and, as a consequence, the capacitive component of the coating (CPE-T1) significantly increase; c) the characteristic frequency of the HF process at the initial exposure stage is $4.8 \mathrm{kHz}$ but increases after 60 days of exposure.

- A characteristic feature of the MF process is that it manifests itself at exposure times of 60 days or more. The active resistance R2 shows a decreasing trend. Similarly to the HF process, an increase in the capacitive component of the coating (CPE-T2) is observed, and the characteristic frequency increases tenfold in the course of the MF process development (from 18 to $180 \mathrm{~Hz}$ ).

- The potential of the steel substrate under the coating during exposure in $3 \% \mathrm{NaCl}$ solution diminishes unlike that of the Pt substrate, but even at the longest exposure time it exceeds the corrosion potential of unprotected St3, i.e., $-500 \mathrm{mV}$.

Thus, the data obtained demonstrate the effect of the substrate type (inert or corroding) and products of steel substrate corrosion on the entire set of electrochemical characteristics of the substrate/inert coating system.

\subsubsection{Zn-rich primers on steel and platinum}

The corroding dispersed filler $(\mathrm{Zn})$ is distributed in $\mathrm{Zn}$-rich primers throughout the volume. Some $\mathrm{Zn}$ particles are easily accessible for the corrosive medium while others are temporarily blocked since they are located in deep layers. As a result, the corrosion process develops with a varying rate, which should be reflected in EIS characteristics, and complicates the choice of the EC.

It also follows from the above that the electrochemical behavior of $\mathrm{Zn}$-rich primer layers is controlled by a number of factors, including the thickness of the layers, content of the active metal, and type and properties of the polymer matrix.

Let us consider the effect of the primer layer thickness from the perspective of possible existence of through porosity. Thin single-layer coatings with a high degree of filling (usual for $\mathrm{Zn}$-rich protective coatings) always have through defects and pores [12].

Similarly to the inert coating, let us first consider a thin single-layer primer M-01 on an inert non-corroding Pt substrate (Figures 7 and 8).

The figures show that even at the initial stage, the thin Zn-rich primer layer on a $\mathrm{Pt}$ substrate exposed in $3 \% \mathrm{NaCl}$ solution exhibits two relaxation maxima: $\mathrm{HF}(5-10 \mathrm{kHz})$ and LF $(0.8-5 \mathrm{~Hz})$.

The results of processing the EIS data show that a satisfactory approximation is provided for small exposure times (up to 30 days) by the Mansfeld EC [13] for porous coatings, while its modified version (Table 3 ) ensures approximation in the entire time range (Table 2). 


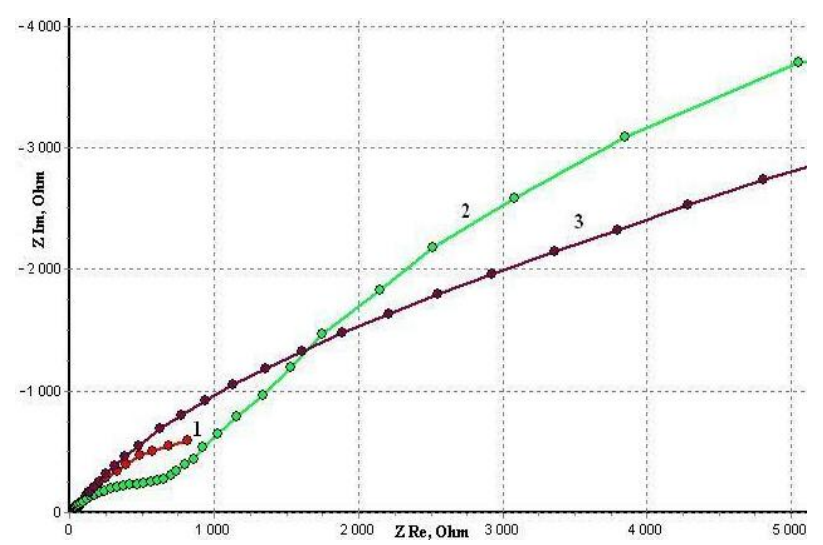

Figure 7. Hodographs of the impedance of thin $(30 \mu \mathrm{m}) \mathrm{Zn}$-rich primer M-01 on a platinum $(\mathrm{Pt})$ substrate after exposure in $3 \% \mathrm{NaCl}$ solution for: 1 - 3 days, 2 - 30 days, 3 - 100 days.

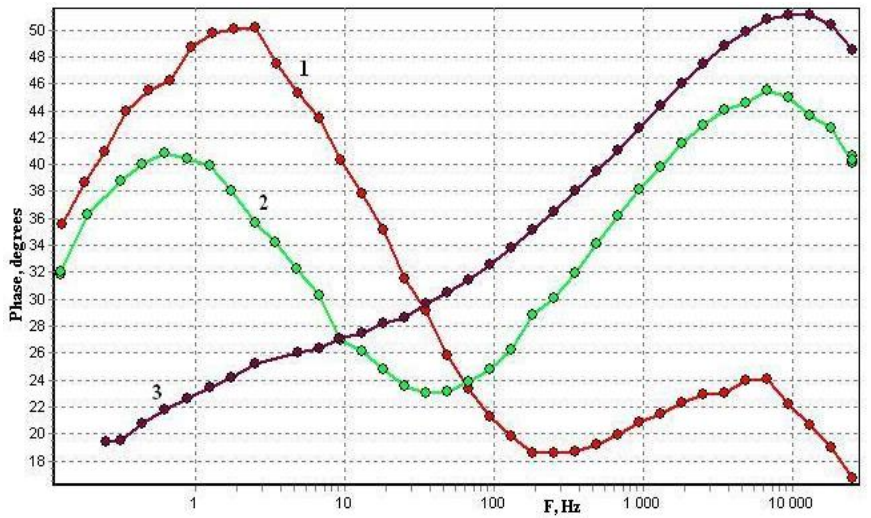

Figure 8. Bode plot for thin $(30 \mu \mathrm{m}) \mathrm{Zn}$-rich primer $\mathrm{M}-01$ on a platinum $(\mathrm{Pt})$ substrate after exposure in $3 \% \mathrm{NaCl}$ solution for: 1 - 3 days, 2 - 30 days, 3 - 100 days.

Table 2. Parameters of the EC components for $30-\mu \mathrm{m}$-thick primer $\mathrm{M}-01$ after exposure in $3 \% \mathrm{NaCl}$ solution for 100 days.

\begin{tabular}{ccccc}
\hline \multirow{2}{*}{ EC parameters } & \multicolumn{3}{c}{ Voigt-Mansfeld equivalent circuit } \\
\cline { 2 - 5 } & $\mathbf{3}$ days & $\mathbf{3 0}$ days & $\mathbf{6 5}$ days & $\mathbf{1 0 0}$ days \\
\hline R1, Ohm & 7.7 & 272.0 & 313.0 & 1025.0 \\
CPE-T1, F & $3.46 \cdot 10^{-5}$ & $7.94 \cdot 10^{-6}$ & $1.60 \cdot 10^{-6}$ & $1.17 \cdot 10^{-6}$ \\
Characteristic frequency of the process, Hz & 4827 & 6707 & 12494 & 9319 \\
$R 2$, Ohm & 38.4 & 554.3 & 749.6 & 2572 \\
CPE-T2, F & $3.77 \cdot 10^{-4}$ & $1.78 \cdot 10^{-5}$ & $7.32 \cdot 10^{-6}$ & $8.49 \cdot 10^{-7}$ \\
Characteristic frequency of the process, $\mathrm{Hz}$ & 1295 & 180 & 670 & 670 \\
CPE-T3, F & 2157 & 11773 & 18996 & 28130 \\
Characteristic frequency of the process, $\mathrm{Hz}$ & 2.5 & $0.92 \cdot 10^{-5}$ & $4.76 \cdot 10^{-5}$ & $2.16^{-5} \cdot 10^{-5}$ \\
\hline Error, $\%$ & 1.33 & 1.40 & 1.8 & 6.7 \\
\hline
\end{tabular}


Table 3. Equivalent circuits for the description of electrochemical properties of thin protective primers on a steel substrate at large time of exposure in $3 \% \mathrm{NaCl}$ solution at $25^{\circ} \mathrm{C}$.

Dansfeld circuit [13] for porous coatings

The results of approximation of hodographs and frequency plots using various circuits are shown below (Figures 9-14 and Table 4).

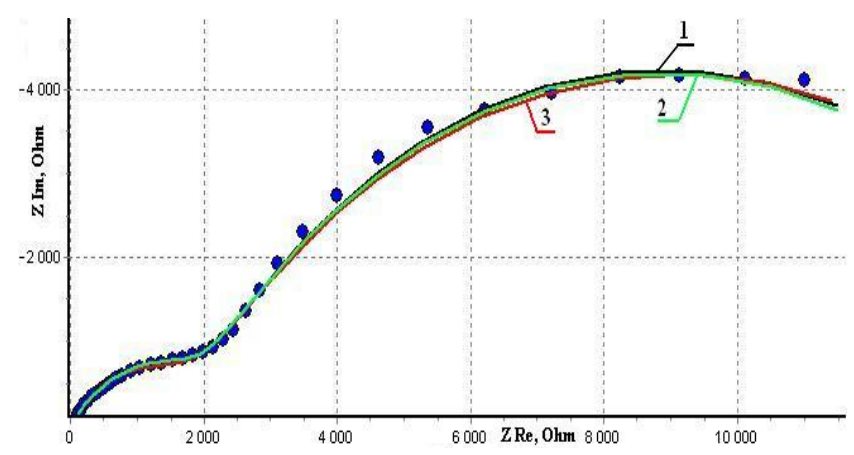

Figure 9. Impedance hodograph of thin (30 $\mu \mathrm{m}) \mathrm{Zn}$-rich primer M-01 on a steel (St3) substrate in $3 \% \mathrm{NaCl}$ solution for 100 days. Dots - experiment; lines - approximations using Mansfeld (1), Voigt-Mansfeld (2), and Voigt (3) ECs.

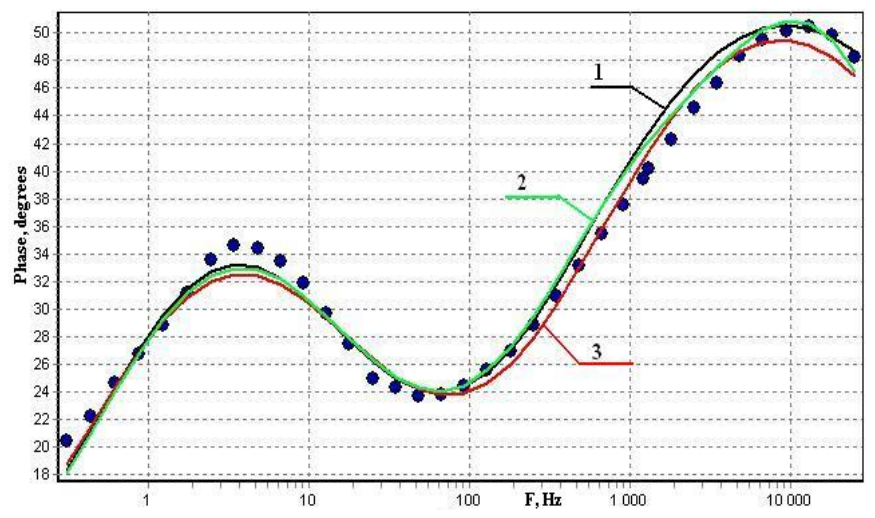

Figure 10. Bode plot of the impedance of thin $(30 \mu \mathrm{m}) \mathrm{Zn}$-rich M-01 primer on a steel (St3) substrate in $3 \% \mathrm{NaCl}$ solution for 100 days. Dots - experiment; lines - approximations using Mansfeld (1), Voigt-Mansfeld (2), and Voigt (3) ECs. 
More complex evolution can be expected for the same Zn-rich primer M-01 layer on a corroding St3 substrate since such a coating/substrate system should be considered as a twoanode system. However, most likely, the activation and fading of the oxidation processes in the filler and substrate would not be observed concurrently. Namely, at the initial state of exposure in a corrosive medium, primarily corrosion of the protector $\mathrm{Zn}$ additive should occur, while development of corrosion of the steel substrate is not likely. At the final stage, as $\mathrm{Zn}$ is exhausted, its contribution to the galvanic protection of the substrate should diminish which potentially creates conditions for the manifestation of underfilm corrosion of the steel substrate.

Due to these circumstances, the selection of a versatile EC is a complex task. So, we considered two approximations of EIS data based on different ECs (Table 3).

The impedance of EC components of thin Zn-protective layer on St3 calculated using various circuits is displayed below (Table 4).

Table 4. Parameters of EC components for 30- $\mu \mathrm{m}$-thick primer M-01 on a steel substrate after exposure in $3 \% \mathrm{NaCl}$ solution for 100 days calculated using various circuits.

\begin{tabular}{cccc}
\hline \multirow{2}{*}{ EC parameters } & \multicolumn{3}{c}{ Equivalent circuit } \\
\cline { 2 - 4 } & Mansfeld & Voigt & Voigt-Mansfeld \\
\hline$R 1$, Ohm & $2.26 \cdot 10^{3}$ & $1.90 \cdot 10^{3}$ & $1.36 \cdot 10^{2}$ \\
CPE-T1, F & $2.21 \cdot 10^{-6}$ & $2.40 \cdot 10^{-6}$ & $6.11 \cdot 10^{-7}$ \\
$\begin{array}{c}\text { Characteristic frequency } \\
\text { of the process, Hz }\end{array}$ & 9319 & 9319 & 9319 \\
$R 2$, Ohm & $1.37 \cdot 10^{4}$ & $1.40 \cdot 10^{4}$ & $2.02 \cdot 10^{3}$ \\
$\begin{array}{c}\text { CPE-T2, F } \\
\text { Characteristic frequency } \\
\text { of the process, Hz } \\
R 3, \text { Ohm }\end{array}$ & $2.38 \cdot 10^{-5}$ & $2.54 \cdot 10^{-5}$ & $1.61 \cdot 10^{-6}$ \\
$\begin{array}{c}\text { CPE-T3, F } \\
\text { Characteristic frequency } \\
\text { of the process, Hz }\end{array}$ & 3.47 & 3.47 & 1799 \\
\hline Error, $\%$ & & $1.38 \cdot 10^{4}$ \\
\hline
\end{tabular}

The most easily comprehensible and sensitive to the quality of EIS data approximation are the frequency plots of the loss tangent (Bode plots) (Figures 11-13).

The data displayed in the table and figures (Figures 11-13) show that the approximation errors in the three circuits are similar (1.45-1.98\%), but the smallest error $(1.45 \%)$ is obtained if the Voigt-Mansfeld hybrid circuit is used. However, this result is quite expected since this circuit contains a larger $(+2)$ number of elements. Additional 
arguments in favor of a preferable choice can be obtained by analyzing Zn protector primer layers of various thickness.

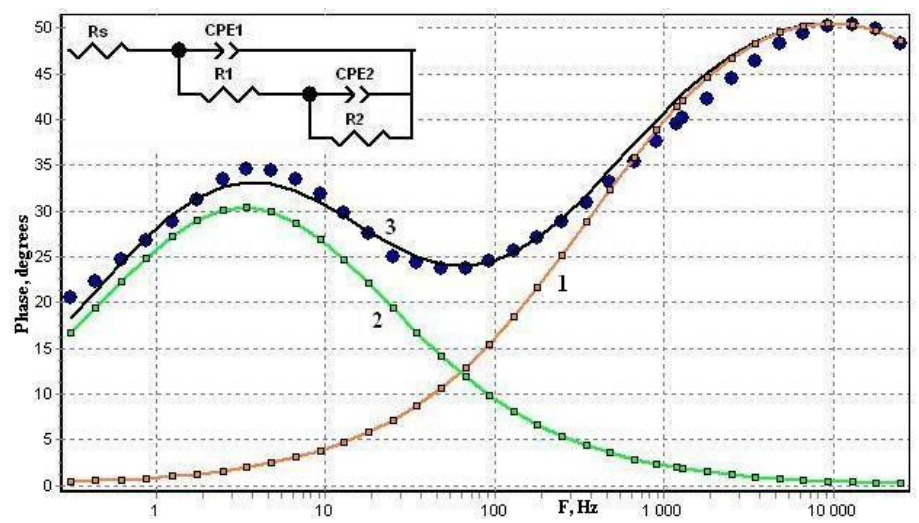

Figure 11. Bode plot for thin $(30 \mu \mathrm{m}) \mathrm{Zn}$-rich primer M-01 on a steel (St3) substrate after exposure in $3 \% \mathrm{NaCl}$ solution for 100 days and its approximation using the Mansfeld circuit (3) with separation into HF (1) and LF (2) components.

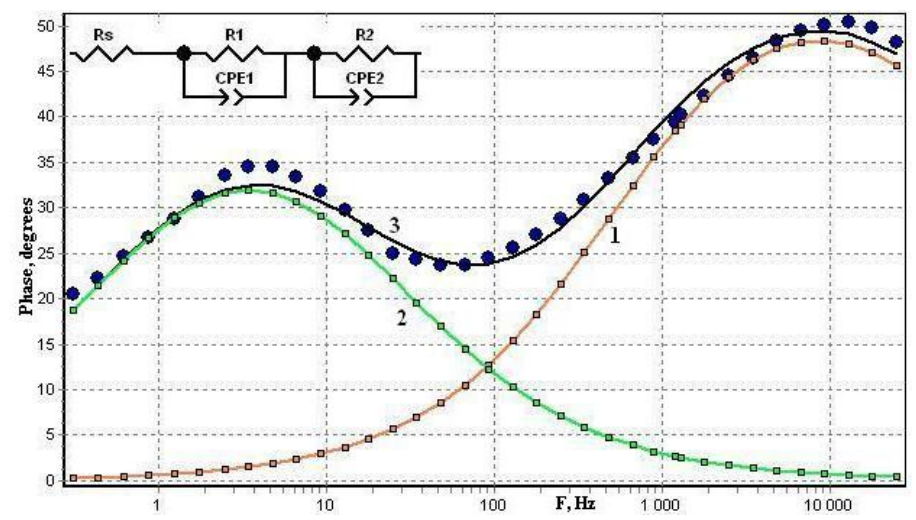

Figure 12. Bode plot for thin $(30 \mu \mathrm{m}) \mathrm{Zn}$-rich primer M-01 on a steel (St3) substrate after exposure in $3 \% \mathrm{NaCl}$ solution for 100 days and its approximation using the Voigt circuit (3) with separation into HF (1) and LF (2) components.

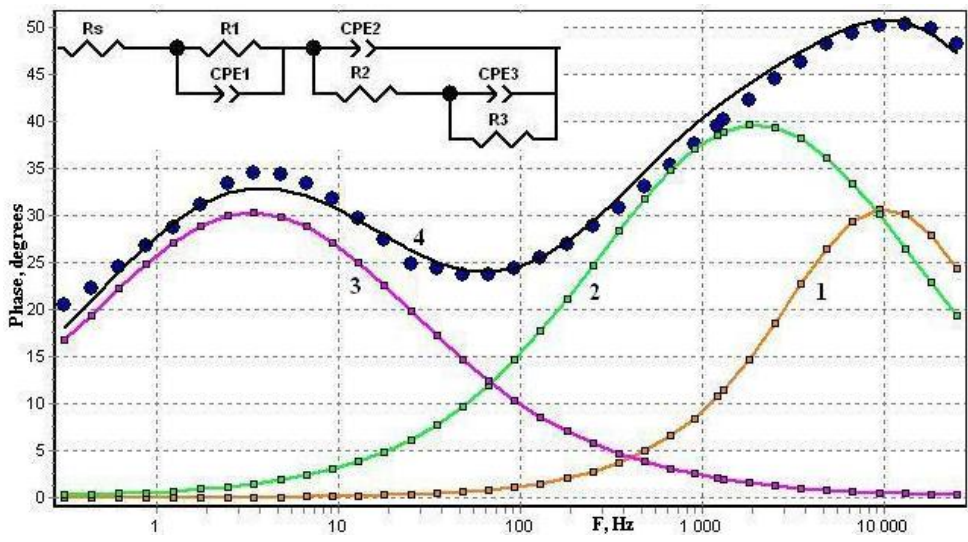

Figure 13. Bode plot for thin $(30 \mu \mathrm{m}) \mathrm{Zn}$-rich primer M-01 on a steel (St3) substrate after exposure in $3 \% \mathrm{NaCl}$ solution for 100 days and its approximation using Voigt-Mansfeld circuit (4) with separation into HF (1), MF (2), and LF (3) components. 


\subsubsection{Estimation of the correctness of the models for porous and low-porosity layers}

Since the primer layer is applied in more than one stage, as a result of which through defects are covered, it is reasonable to check the quality of approximation for layers with an increased thickness using models of porous and low-porosity primers.

Examples of such models are the Voigt-Mansfeld hybrid model considered above, which yielded the lowest approximation error for thin layers, and the model of a volumefilled composite material, which may be referred to as a "3-phase Voigt model".
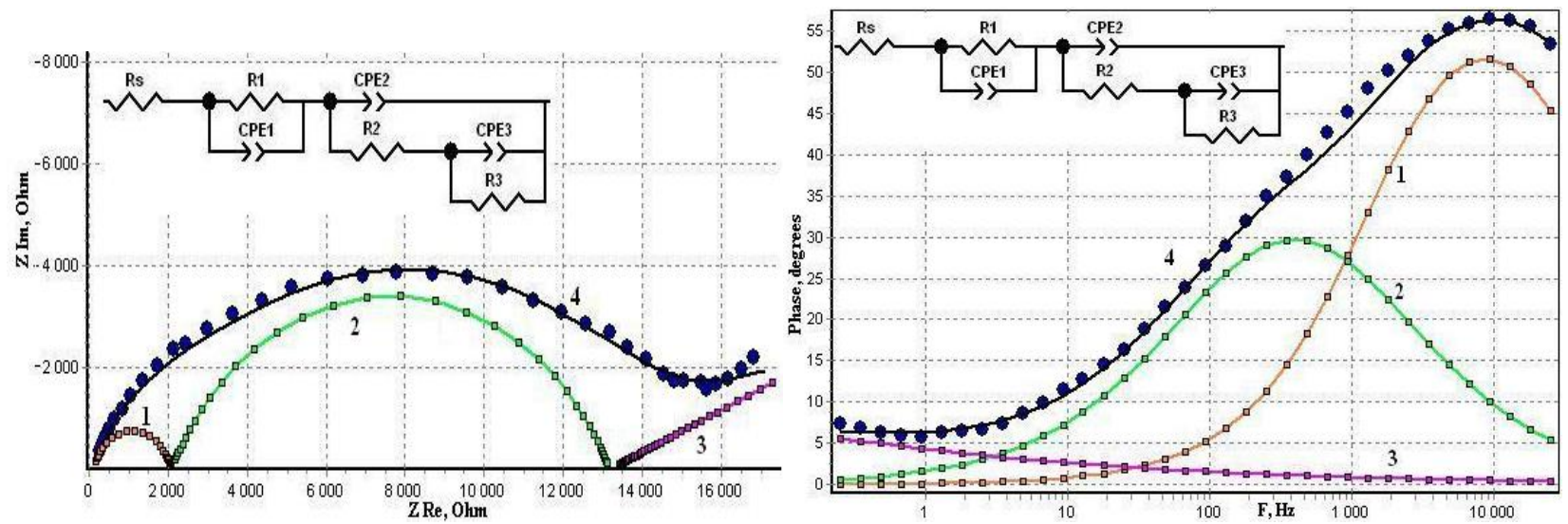

Figure 14. Hodograph of impedance and the Bode plot of multilayered (100 $\mu \mathrm{m}) \mathrm{Zn}$-rich primer M-01 on a steel (St3) substrate after exposure in $3 \% \mathrm{NaCl}$ solution for 100 days and their approximation using the Voigt-Mansfeld circuit for porous coatings (4) with separation of the HF (1), MF (2), and LF (3) components.
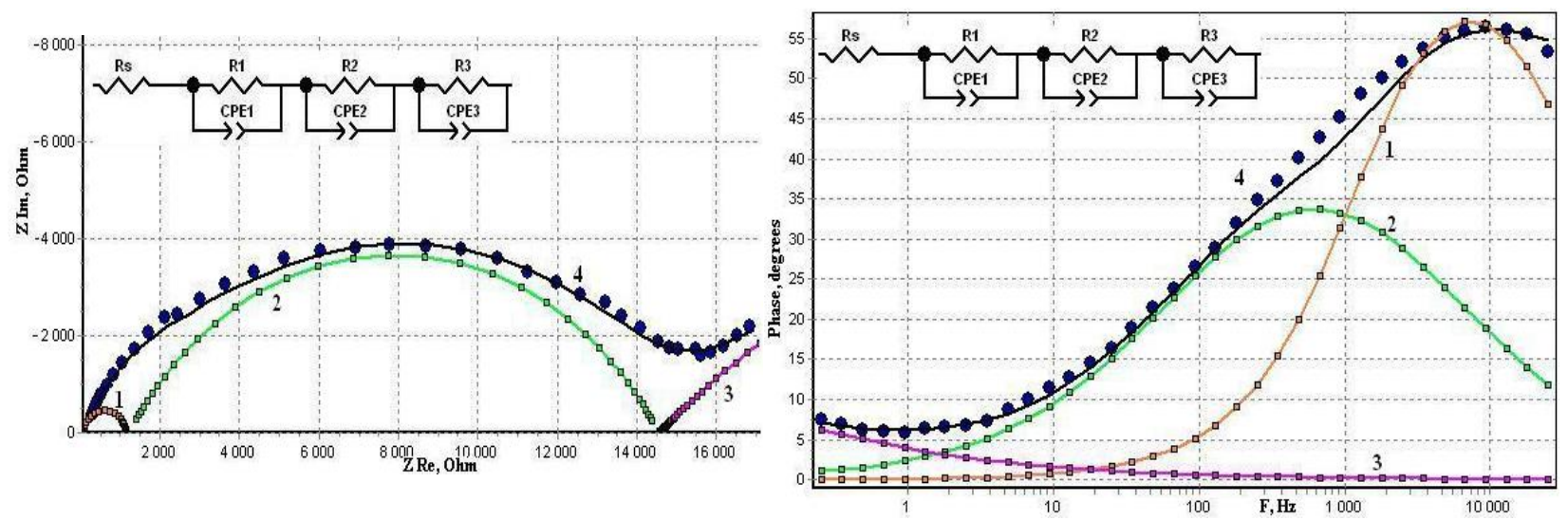

Figure15. Hodograph of impedance and the Bode plot of multilayered (100 $\mu \mathrm{m}) \mathrm{Zn}$-rich primer $\mathrm{M}-01$ on a steel (St3) substrate after exposure in $3 \% \mathrm{NaCl}$ solution for 100 days and their approximation using the 3-phase Voight circuit for low-porosity coatings (4) with separation of the HF (1), MF (2), and LF (3) components.

The latter model represents a Zn protective primer layer as a 3-phase system with bulk or alternating laminar phases with different dielectric properties. Examples of such phases are: a) a polymer matrix; b) Zn powder particles initially incorporated into the matrix; c) particles of hydrated $\mathrm{Zn}$ oxides, which are produced as a result of $\mathrm{Zn}$ oxidation under the 
effect of a corrosive medium. This model is very flexible since it does not $a b$ initio strictly relate relaxation phenomena with certain processes, for example, capillary transport that can change considerably if multilayer coatings are applied.

The results of approximation using the two circuits under consideration are displayed below (Figures 14 and 15, Table 5).

Table 5. EC components calculated for primer M-01 with enhanced thickness $(100 \mu \mathrm{m})$ applied in several layers after exposure in $3 \% \mathrm{NaCl}$ solution for 100 days.

\begin{tabular}{ccc}
\hline \multirow{2}{*}{ EC parameters } & \multicolumn{2}{c}{ Equivalent circuit } \\
\cline { 2 - 3 } & Voigt-Mansfeld & 3-phase Voigt model \\
\hline$R 1$, Ohm & $1.97 \cdot 10^{3}$ & $1.16 \cdot 10^{3}$ \\
CPE-T1, F & $2.65 \cdot 10^{-7}$ & $1.70 \cdot 10^{-7}$ \\
CPE-Ph1 & 0.83 & 0.92 \\
Characteristic frequency of the & 9319 & 6707 \\
process, Hz & $1.11 \cdot 10^{4}$ & $1.33 \cdot 10^{4}$ \\
$R 2$, Ohm & $9.68 \cdot 10^{-7}$ & $1.31 \cdot 10^{-6}$ \\
CPE-T2, F & 0.70 & 0.64 \\
CPE-Ph2 & 483 & 670 \\
Characteristic frequency of the & $1.62 \cdot 10^{10}$ & $3.34 \cdot 10^{4}$ \\
process, Hz & $0.20 \cdot 10^{-3}$ & $0.24 \cdot 10^{-3}$ \\
$R 3$, Ohm & 0.25 & 0.44 \\
CPE-T3, F & 0.25 & 0.25 \\
CPE-Ph3 & 2.39 & 1.13 \\
\hline Characteristic frequency of the \\
process, Hz
\end{tabular}

It can be seen that both the hodographs and frequency plots can be approximated using either of the two circuits and the root-mean-square deviations between the calculated and experimental dependences for both ECs are not very different (2.39 and 1.13). However, if the Voigt-Mansfeld hybrid circuit is employed, apparent disagreement is observed at low frequencies, and the calculated values of some EC components lose physical meaning (Table 5).

This finding allows us to make the conclusion that the best approximation for thicklayer primer coatings applied in more than one stage, which also preserves physically justified values of EC components, is provided by the 3-phase Voigt model with wellseparated characteristic frequencies. 
It should be noted that the use of the Voigt model does not involve any formal restrictions on the disposition of composite material components. It can be applied to both a volume-filled and laminated inhomogeneous composite material. It is for this reason that the model under consideration provides a fairly correct description for multilayered coatings made of volume-filled polymer materials.

It is believed that this approach can be applied to other types of multilayered anticorrosion composite polymer coatings.

\subsection{Composite coatings}

As noted above, of special interest for highly-efficient anticorrosion protection are multilayered coatings that consist of specialized layers with various composition and properties.

Based on the EIS results considered above and estimation of the ECs optimal for individual layers of the composite coating, it may be expected that the EC which may be adequate to describe the multilayered coating is an additive one. The total impedance of the coating, which is also an additive quantity $\left(Z=\Sigma\left(Z_{i}\right)\right)$, is determined by the number $(i)$, thickness, and composition of the coating layers.

However, the hypothesis regarding the full additivity of the composite coating impedance requires a verification, since the composition of the inner solution in polymers can differ from that of the outside solution [14], and hence, the $\mathrm{Zn}$ protective primer layer would be subject to different conditions.

Displayed below are the primary data of EIS kinetics (Figures 16 and 17) and results of processing these data for a composite coating M-01 $(60 \mu \mathrm{m})+\mathrm{R}-5095(100 \mu \mathrm{m})$ on a steel substrate upon exposure in $3 \% \mathrm{NaCl}$ solution for 344 days at a temperature of $20^{\circ} \mathrm{C}$ and for 7 days at $60^{\circ} \mathrm{C}$.

\subsubsection{EIS data for composite coatings}

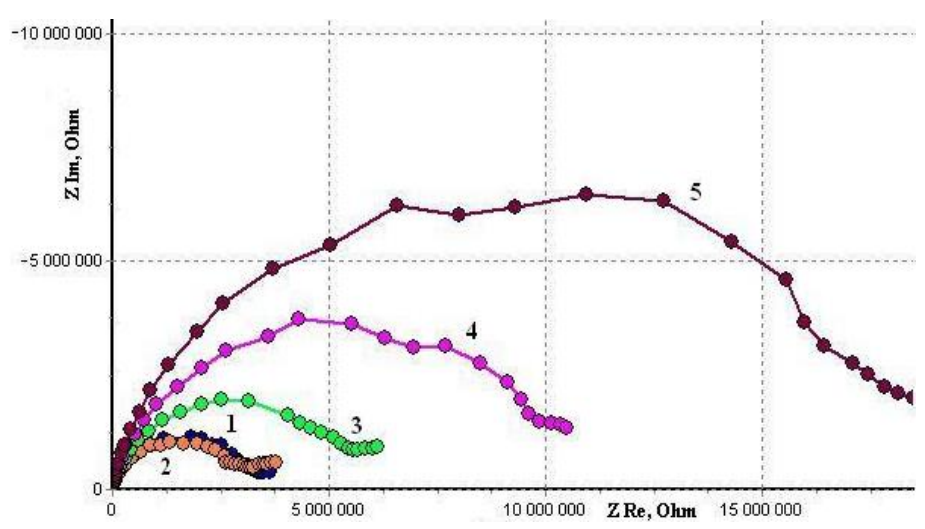

Figure 16. Impedance hodographs of a composite coating (M-01 $(60 \mu \mathrm{m})+$ R-5095 $(100 \mu \mathrm{m}))$ on a steel (St3) substrate upon exposure in $3 \% \mathrm{NaCl}$ solution for: 1 - 30 days, $2-100$ days, 3 - 200 days, $4-344$ days, and $5-351$ days. 


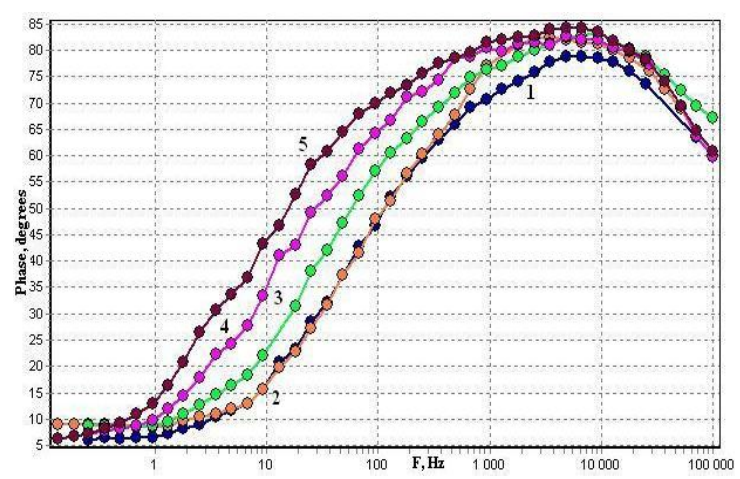

Figure 17. Bode plots for a composite coating (M-01 $(60 \mu \mathrm{m})+\mathrm{R}-5095(100 \mu \mathrm{m}))$ on a steel (St3) substrate upon exposure in 3\% $\mathrm{NaCl}$ solution for: $1-30$ days, $2-100$ days, $3-200$ days, $4-344$ days, and $5-351$ days.

The presented results show that both the hodograph shape and the Bode frequency plots feature a complex structure at all exposure times. This is especially well pronounced at large times of exposure in the corrosive medium.

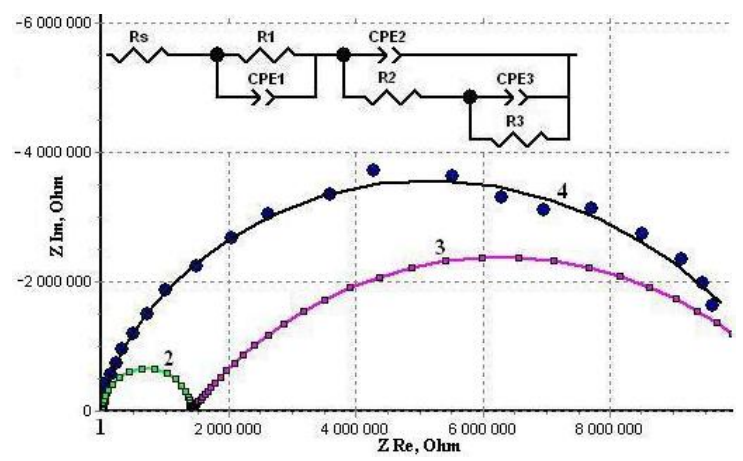

Figure 18. Impedance hodograph of a composite coating (Zn-rich protective primer M-01 + inert upper coating R-5095) on a steel (St3) substrate after exposure in $3 \% \mathrm{NaCl}$ solution for 344 days $\left(\right.$ at $20^{\circ} \mathrm{C}$ ) and its approximation using the Voigt-Mansfeld hybrid circuit (4) with separation of the HF (1), MF (2), and LF (3) components.

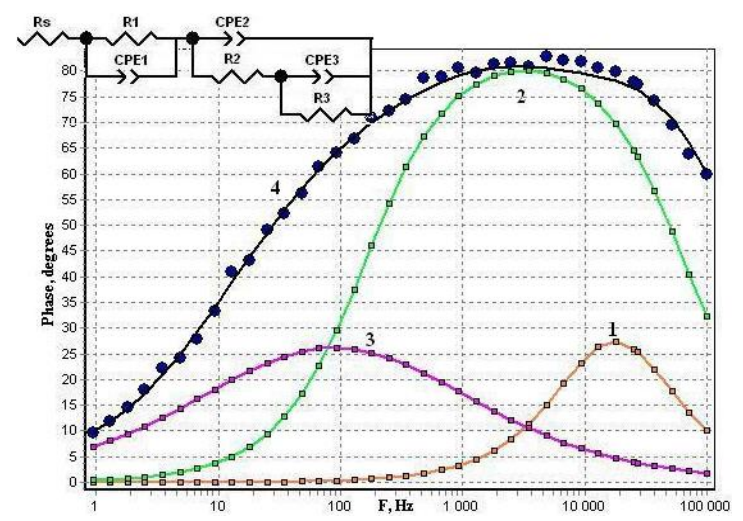

Figure 19. Bode plot a composite coating (Zn-rich protective primer M-01 + inert upper coating R-5095) on a steel (St3) substrate after exposure in 3\% $\mathrm{NaCl}$ solution for 344 days (at $20^{\circ} \mathrm{C}$ ) and its approximation using the Voigt-Mansfeld hybrid circuit (4) with separation of the HF (1), MF (2), and LF (3) components. 


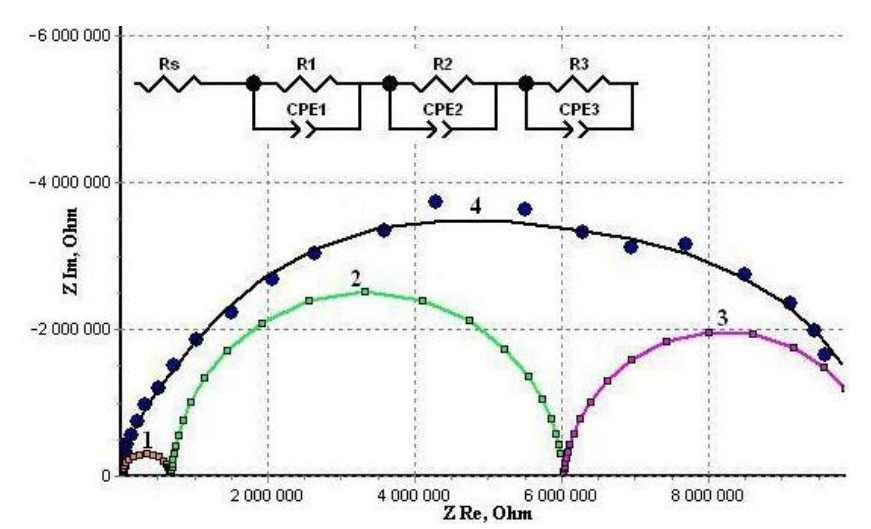

Figure 20. Impedance hodograph of a composite coating (Zn-rich protective primer M-01 + inert upper coating R-5095) on a steel (St3) substrate after exposure in 3\% $\mathrm{NaCl}$ solution for 344 days (at $20^{\circ} \mathrm{C}$ ) and its approximation using the 3-phase Voigt circuit (4) with separation of the HF (1), MF (2), and LF (3) components.

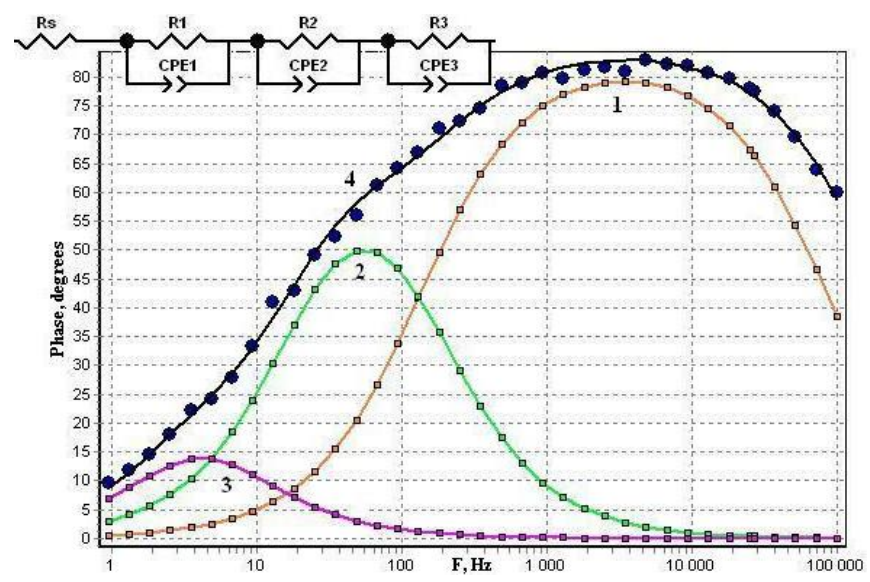

Figure 21. Bode plot for a composite coating (Zn-rich protective primer $\mathrm{M}-01+$ inert upper coating R-5095) on a steel (St3) substrate after exposure in $3 \% \mathrm{NaCl}$ solution for 344 days (at $20^{\circ} \mathrm{C}$ ) and its approximation using the 3-phase Voigt circuit (4) with separation of the HF (1), MF (2), and LF (3) components.

It should be noted that at large exposure time, an LF process is detected with a characteristic frequency in the range of $1-5 \mathrm{~Hz}$, which can be related to the development of the electrochemical process of Zn oxidation.

Experimental data for a composite coating consisting of M-01 $(60 \mu \mathrm{m})+\mathrm{R}-5095$ $(100 \mu \mathrm{m})$ and their approximation using various ECs presented in Table 3, including the Voigt-Mansfeld hybrid circuit and 3-phase Voigt circuit, are displayed below (Figures 1821 and Table 6).

As the data displayed in Figures 18 and 19 shows, the Voigt-Mansfeld hybrid EC, like in the case of a multilayered primer (Table 5), fails to provide an adequate description of the experimental data.

At the same time, the Voigt EC for 3-phase composites, similarly to multilayered primers, provides a correct description in the entire time range including large exposure 
times and, which is also of importance, for various temperatures in the range of $20-60^{\circ} \mathrm{C}$ (Figures 22-27 and Table 7).

Table 6. Calculated EC components for a composite coating (Zn-rich protective primer M-01 + inert upper coating R-5095) with a thickness of $60 \mu \mathrm{m}$ and $100 \mu \mathrm{m}$, respectively, after exposure in $3 \% \mathrm{NaCl}$ solution for 344 days at a temperature of $20-25^{\circ} \mathrm{C}$.

\section{EC parameters}

\begin{tabular}{ccc}
\hline$R 1, \mathrm{Ohm}$ & $2.82 \cdot 10^{3}$ & $6.82 \cdot 10^{5}$ \\
CPE-T1, F & $5.97 \cdot 10^{-9}$ & $2.65 \cdot 10^{-9}$ \\
CPE-Ph1 & 1.42 & 0.94 \\
Characteristic frequency of the & 17992 & 3474 \\
process, Hz & $1.41 \cdot 10^{6}$ & $5.34 \cdot 10^{6}$ \\
$R 2, \mathrm{Ohm}$ & $9.29 \cdot 10^{-10}$ & $2.03 \cdot 10^{-9}$ \\
CPE-T2, F & 0.96 & 0.96 \\
CPE-Ph2 & 3474 & 48.3 \\
Characteristic frequency of the & $9.73 \cdot 10^{6}$ & $4.34 \cdot 10^{6}$ \\
process, Hz & $7.33 \cdot 10^{-9}$ & $1.40 \cdot 10^{-8}$ \\
R3, Ohm & 0.58 & 0.94 \\
CPE-T3, F & 93.2 & 3.47 \\
CPE-Ph3 & 3.92 & 1.77 \\
Characteristic frequency of the \\
process, Hz
\end{tabular}

\section{Equivalent circuit}

\section{Voigt-Mansfeld}

\section{3-phase Voigt model}

$6.82 \cdot 10^{5}$ 


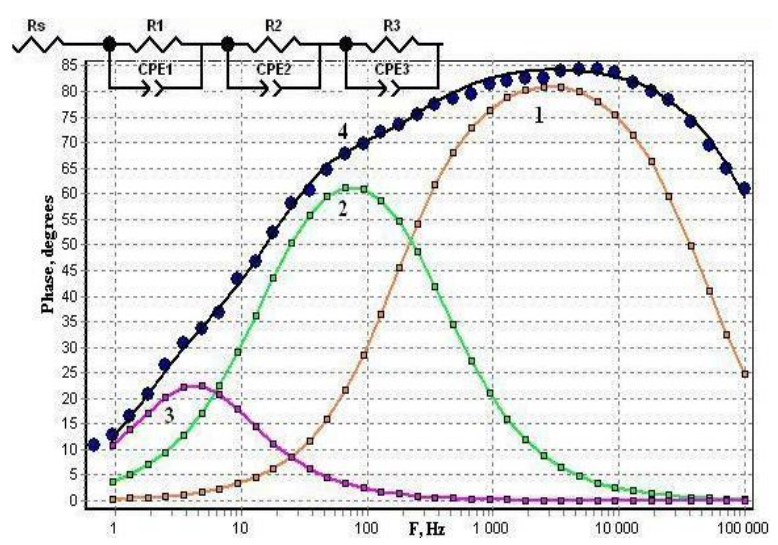

Figure 23. Bode plot for a composite coating (Zn-protective primer M-01 + upper inert coating R-5095) on a steel ( $\mathrm{St3}$ ) substrate after exposure in $3 \% \mathrm{NaCl}$ solution for 344 days (at $20-25^{\circ} \mathrm{C}$ ) and next at 7 days (at $60^{\circ} \mathrm{C}$ ) and its approximation (4) with separation of the HF (1), MF (2), and LF (3) components. Data obtained at $20^{\circ} \mathrm{C}$.

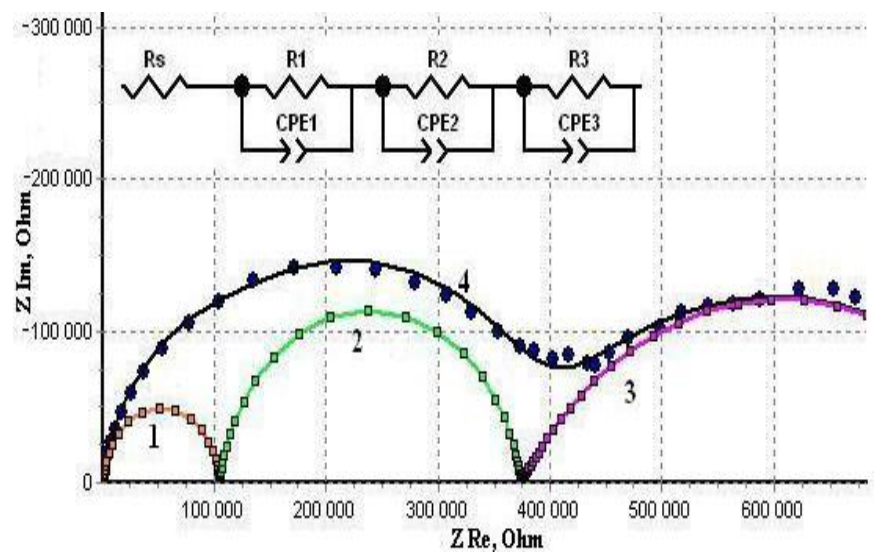

Figure 24. Impedance hodograph of a composite coating (Zn-protective primer M-01 + upper inert coating R-5095) on a steel (St3) substrate after exposure in $3 \% \mathrm{NaCl}$ solution for 344 days (at $20-25^{\circ} \mathrm{C}$ ) and next at 7 days (at $60^{\circ} \mathrm{C}$ ) and its approximation (4) with separation of the $\mathrm{HF}(1), \mathrm{MF}(2)$, and LF (3) components. Data obtained at $40^{\circ} \mathrm{C}$.

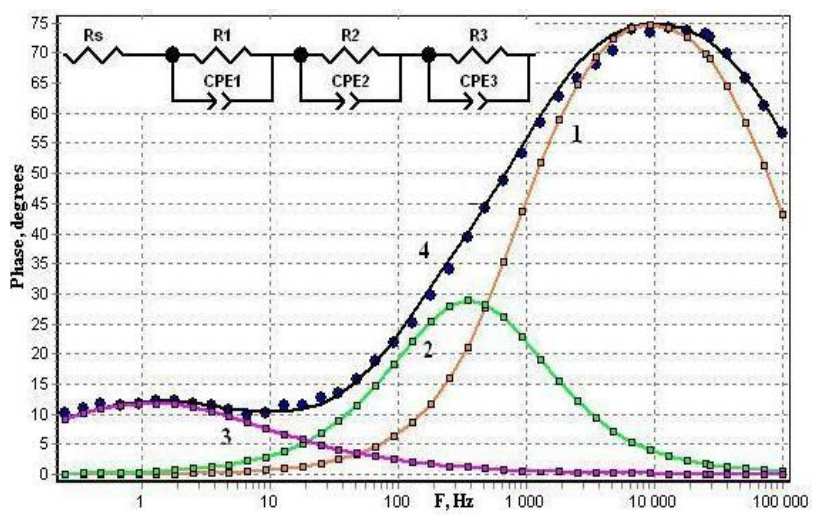

Figure 25. Bode plot for a composite coating (Zn-protective primer M-01 + upper inert coating R-5095) on a steel ( $\mathrm{St3}$ ) substrate after exposure in $3 \% \mathrm{NaCl}$ solution for 344 days (at $20-25^{\circ} \mathrm{C}$ ) and next at 7 days (at $60^{\circ} \mathrm{C}$ ) and its approximation (4) with separation of the HF (1), MF (2), and LF (3) components. Data obtained at $40^{\circ} \mathrm{C}$. 


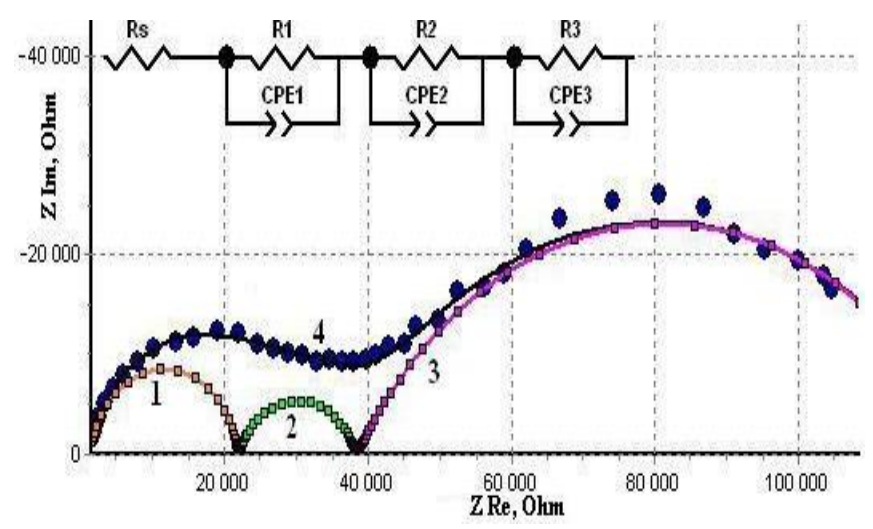

Figure 24. Impedance hodograph of a composite coating (Zn-protective primer M-01 + upper inert coating R-5095) on a steel (St3) substrate after exposure in 3\% $\mathrm{NaCl}$ solution for 344 days (at $20-25^{\circ} \mathrm{C}$ ) and next at 7 days (at $60^{\circ} \mathrm{C}$ ) and its approximation (4) with separation of the $\mathrm{HF}(1), \mathrm{MF}(2)$, and LF (3) components. Data obtained at $60^{\circ} \mathrm{C}$.

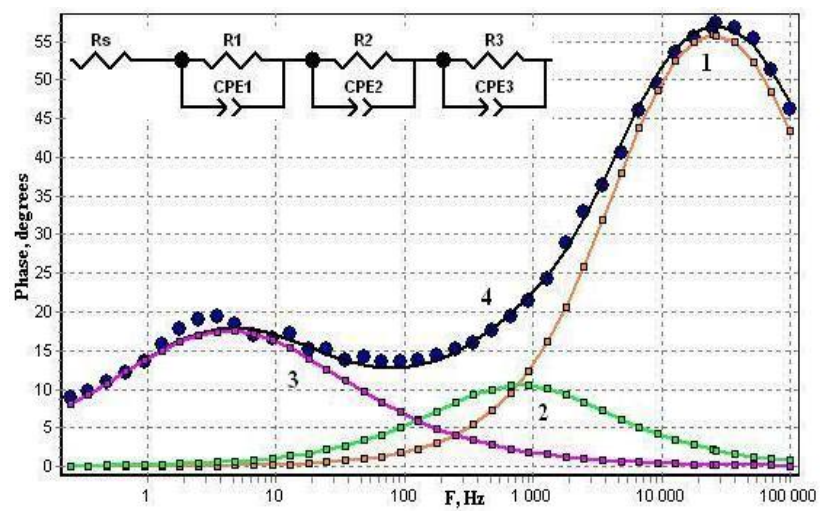

Figure 25. Bode plot for a composite coating (Zn-protective primer M-01 + upper inert coating R-5095) on a steel ( $\mathrm{St3}$ ) substrate after exposure in $3 \% \mathrm{NaCl}$ solution for 344 days (at $20-25^{\circ} \mathrm{C}$ ) and next at 7 days (at $60^{\circ} \mathrm{C}$ ) and its approximation (4) with separation of the $\mathrm{HF}(1)$, MF (2), and LF (3) components. Data obtained at $60^{\circ} \mathrm{C}$.

Thus, the use of the Voigt EC for 3-phase composite materials provides a correct description of EIS data and identification of relaxation processes in the entire range of exposure times and temperatures.

To summarize, the conclusion can be drawn that the most universal description of protective thick polymer coatings should be based on the presentation of such coatings as multiphase layered volume-filled composite materials. This approach enables an adequate processing of EIS data at various temperatures for all the systems we studied, including inert layers on St3 and Pt, thin and multilayered Zn-rich primer layers, and multilayered coatings consisting of such layers.

The EC evolution in the course of exposure in a corrosive medium is also logical. The key physicochemical parameter in forecasting the evolution of circuits is the change in the phase composition of the layers of polymer protective coatings under the effect of a corrosive 
medium. The second factor in the transition from model systems to actual coatings is that a layered composite material with low porosity is produced upon applying the coating.

Thus, the EC based on a combination of Voigt elements provides a correct approximation of EIS results in the entire range of exposure times and for the transition from thin coatings to multilayered structures.

Table 7. EC parameters calculated using the 3-phase Voigt circuit for a composite coating (Zn-protective primer M-01 + upper inert coating R-5095) on a steel (St3) substrate after exposure in 3\% $\mathrm{NaCl}$ solution for 344 days (at $20-25^{\circ} \mathrm{C}$ ) and 7 days $\left(\right.$ at $60^{\circ} \mathrm{C}$ )

\begin{tabular}{cccc}
\hline \multirow{2}{*}{ EC parameters } & \multicolumn{3}{c}{ Temperature of measurement, ${ }^{\circ} \mathbf{C}$} \\
\cline { 2 - 4 } & $\mathbf{2 0}$ & $\mathbf{4 0}$ & $\mathbf{6 0}$ \\
\hline $\begin{array}{c}\text { R1, Ohm } \\
\text { CPE-T1, F }\end{array}$ & $3.59 \cdot 10^{5}$ & $1.04 \cdot 10^{5}$ & $2.08 \cdot 10^{4}$ \\
$\begin{array}{c}\text { Characteristic frequency of } \\
\text { the process, Hz }\end{array}$ & $3.00 \cdot 10^{-9}$ & $2.42 \cdot 10^{-9}$ & $5.74 \cdot 10^{-9}$ \\
$R 2$, Ohm & 3474 & 10000 & 25000 \\
$\begin{array}{c}\text { CPE-T2, F } \\
\text { Characteristic frequency of } \\
\text { the process, Hz }\end{array}$ & $7.17 \cdot 10^{6}$ & $2.69 \cdot 10^{5}$ & $1.65 \cdot 10^{4}$ \\
$R 3$, Ohm & $1.82 \cdot 10^{-9}$ & $7.27 \cdot 10^{-9}$ & $1.46 \cdot 10^{-7}$ \\
CPE-T3, F & 67 & 347 & 671 \\
Characteristic frequency of \\
the process, Hz
\end{tabular}

A significant advantage of the Voigt circuits is that identification of frequencies characteristic of relaxation processes is simplified. Three groups of processes have been found:

1. HF processes are observed in all the systems under study on both Pt and St3 substrates with both inert and corroding ( $\mathrm{Zn}$ ) filler. The frequency range is from $3.5 \mathrm{kHz}$ to $9.3 \mathrm{kHz}$. With an increase in temperature, the frequency of the HF process increases to $25 \mathrm{kHz}$.

2. MF processes are only observed in the systems that contain a corroding anode (Zn or St3). The frequency range is from 48 to $670 \mathrm{~Hz}$. The frequency of the MF process increases with an increase in temperature.

3. LF processes emerge in multilayered systems at large times of exposure in a corrosive medium. The frequency range is from $0.25 \mathrm{~Hz}$ to $93 \mathrm{~Hz}$. The LF frequency does not change with an increase in temperature. 
However, the issue of additional criteria required to associate the absorption maxima with specific physicochemical processes, which occur in such a complex system as a composite coating, is still unresolved.

In our opinion, to identify these processes, tests should be conducted with additional factors as a result of which the contributions of processes to EIS will change. One of such factors can be the variation of temperature that affects diffusion and corrosion in different ways.

In principle, the temperature modes of exposure and measurement can differ. Measurements of EIS at various temperatures after exposure under the same conditions are more informative. Effective activation energies can be used as indicators of the process nature.

3.3. Effective activation energy upon exposure at the same temperature-time cycles of exposure

As noted above, three main relaxation processes have been identified for the composite coatings that consist of a primer layer with an active $\mathrm{Zn}$ filler and an upper inert layer on a steel substrate. The characteristics of the effective activation energy for these processes calculated using the 3-phase Voigt circuit are displayed below (Table 8).

Table 8. Activation energies and frequencies of characteristic processes calculated using the 3-phase Voigt circuit for a composite polymer coating (Zn-protective primer M-01 + upper inert coating R-5095) on a steel substrate after exposure in $3 \% \mathrm{NaCl}$ solution for 344 days (at $20-25^{\circ} \mathrm{C}$ ) and 7 days $\left(\right.$ at $60^{\circ} \mathrm{C}$ ).

\begin{tabular}{|c|c|c|c|}
\hline \multirow{2}{*}{ Process parameters } & \multicolumn{3}{|c|}{$\begin{array}{l}\text { Frequency range of characteristic relaxation } \\
\text { processes, } \mathrm{Hz}\end{array}$} \\
\hline & $\mathbf{1}-\mathbf{1 0}$ & $100-1000$ & $5000-100000$ \\
\hline Effective activation energy, $\mathrm{kJ} / \mathrm{mol}$ & 67 & 112 & 75 \\
\hline Characteristic frequency of the process, $\mathrm{Hz}$ & 2.5 & 480 & 25000 \\
\hline
\end{tabular}

It should be noted that increasing the EC complexity does not provide qualitatively new information. For example, if a 4-phase circuit is used, the parameters of the HF и LF processes do not change and only the MF process splits into two processes with close values of activation energies (116-118 kJ/mol) and close characteristic frequencies. Based on this observation and applying Occam's razor principle [15], we limit our consideration with a simple 3-phase Voigt circuit.

Calculations show that the activation energies of the LF $(1-5 \mathrm{~Hz})$ and $\mathrm{HF}(25-5 \mathrm{kHz})$ processes are close to each other $(\sim 65-75 \mathrm{~kJ} / \mathrm{mol})$ and are characteristic of the diffusion of low-molecular weight substances, including water $(40-70 \mathrm{~kJ} / \mathrm{mol})$, in polymers. At the same time, the process observed in the MF region $(67-670 \mathrm{~Hz})$ features a significantly higher activation energy $(112 \mathrm{~kJ} / \mathrm{mol})$ characteristic of chemical reactions [16, Table 36.3]. 
Taking into account that if $\mathrm{Zn}$ protector primers and composite coatings are used, underfilm corrosion of the steel substrate is not observed after removal of the coating, it was proposed that the medium-frequency (MF) process corresponds to the corrosion of the active solid-phase $\mathrm{Zn}$ additive. The activation energy of the detected LF diffusion process, which is not observed in the case of inert coatings, is characteristic of diffusion, owing to which the process may be classified as diffusion of $\mathrm{Zn}$ corrosion products or water they contain.

\section{Conclusions}

A technique for nondestructive monitoring of physicochemical and corrosion processes in composite polymer protective coatings have been developed. It is based on comparative electrochemical impedance spectroscopy (EIS) on various metal substrates (corroding and inert) at various temperatures and identification of the corrosion processes using characteristic frequencies, their evolution at various stages of the corrosion process, and estimates of effective activation energies.

It appears that the suggested development of electrochemical impedance spectrometry of composite coatings may be used as a basis for the development of nondestructive diagnostics and may encourage the improvement of anticorrosion materials with active solidphase additives.

\section{Acknowledgements}

The authors are grateful to K.E. Kasatkin, Cand. Sci. (Chem.), for assistance in methodology.

\section{References}

1. ISO 12944-5, Paints and varnishes. Protection of steel structures against corrosion using protective coating systems. Part 5: Combination of protective paints (in Russian).

2. J.H.W. de Wit, D.H. van der Weijde and G. Ferrari, Corrosion mechanisms in Theory and Practice, 2nd edition, Marcel, Dekker, 2002, Ch. 19 (Organic Coatings).

3. T.N. Ostanina, Electrochemical behavior and physicochemical properties of metal-rich coatings, Thesis for the degree of Dr. Sci. (Chem.), specialization 02.00 .05 Electrochemistry, Yekaterinburg, 2003, 226 pp. (in Russian).

4. V.A. Golovin, S.A. Dobriyan, V.A. Shchelkov and A.I. Shcherbakov, Electrochemical Properties of Zn-rich Primers and Composite Coatings on Various Metal Substrates, Int. J. Corros. Scale Inhib., 2020, 9, no. 1, 56-73. doi: 10.17675/2305-6894-2020-9-1-4

5. A. Meroufel and S. Touzain, EIS Characterisation of New Zinc-Rich Powder coatings, Prog. Org. Coat., 2007, 59, no. 3, 197-205. doi: 10.1016/j.porgcoat.2006.09.005

6. J.R. Vilche, E.C. Bucharsky and C.A. Giudice, Application of EIS and SEM to evaluate the influence of pigment shape and content in ZRP formulations on the corrosion prevention of naval steel, Corros. Sci., 2002, 44, no. 6, 1287-1309. doi: 10.1016/S0010$\underline{938 X(01) 00144-5}$ 
7. C. Gabrielli, Use and application of electrochemical impedance techniques, Farnborough, 1990, $78 \mathrm{pp}$.

8. F. Brambilla, E. Campazzi, D. Sinolli and P-J. Lathiere, Accelerated corrosion testing: a prodictive tool, Theses of The Annual Congress of the European Federation of Corrosion (EUROCORR 2018), Cracow, Poland, September 9-13, 2018, 120935.

9. N.A. Poklonskii and N.I. Gorbachuk, Basics of impedance spectroscopy of composites, Minsk, Belarus State University, 2005, 130 pp. (in Russian).

10. ISO 16773-1,2,3,4, Electrochemical impedance spectroscopy (EIS) on high-impedance coated specimens, 2009.

11. V.A. Golovin, S.A. Dobriyan and V.E. Kasatkin, Spectroscopy of electrochemical impedance (EIS) of composite polymer coatings on metal substrates, Int. J. Corros. Scale Inhib., 2018, 7, no. 4, 697-709. doi: 10.17675/2305-6894-2018-7-4-15

12. P. Vertuest, Anti-Corrosion Properties of Zinc Powder Paints Using Nano Zinc Metal Powder, China Coat. J., 2009, July, 24-36.

13. F. Mansfeld, Electrochemical impedance spectroscopy (EIS) as a new tool for investigating methods of corrosion protection, Electrochim. Acta, 1990, 35, no. 10, 1533-1544. doi: 10.1016/0013-4686(90)80007-B

14. V.A. Golovin, A.B. Il'in, A.D. Aliev and V.A. Rabinkov, Mass Transfer of PhosphorusContaining Corrosion Inhibitors in Epoxy Protective Coatings, Prot. Met. Phys. Chem. Surf., 2019, 55, no. 7, 1-7. doi: $10.1134 / \mathrm{S} 2070205119070050$

16. https://en.wikipedia.org/wiki/Occam's_razor

17. Protection of machines, equipment, and structures against corrosion, ageing, and biological damage: Reference book, 1987, 2, Ed.: A.A. Gerasimenko, Moscow, Mashinostroenie, 784 pp. (in Russian). 